Viti i XII ${ }^{\text {të }}$ i Botimit, Nr.1-2,

Dhjetor 2020

\title{
DRONI E ARDHMJA NË DORËN TËNDE
}

\author{
Ervis Qyra*; Artur Prendi*
}

*Departamenti i Inxhinierive, Fakulteti i Shkencave të Aplikuara dhe Ekonomike, Albanian University

Adresë kontakti: ervisqyra@gmail.com

\section{Përmbledhje}

Një dron është një makinë pa pilot e përdorur nga njerëzit përmes kontrolluesve. Integrimi i droneve dhe teknologjisë në internet (IoT) ka krijuar raste të shumta të përdorimit të tyre në aktivitete të ndryshme. Në këtë projekt, ne do të përdorim sensorin me shpejtësi të thjeshtë dhe lehtësisht të disponueshëm mikrokontrolluesin STM32 32-bit, që funksionon në 90MIP me 128KB Flash dhe RAM 20KB. Me këto parametra, droni do të jetë në gjendje të njohë statusin e vërtetë të mjedisit ku do të përdoret. Gjithashtu, do të bëjmë të mundur edhe kontrollin automatik të dronit. Me ndihmën e një motori të vogël servo, droni skanon zonën si në të majtë, ashtu edhe në të djathtë për të gjetur mënyrën më të mirë për t'u kthyer. Përmes përdorimit të sensorit ultrasonik, droni do të kontrollojë prezencën e pengesave dhe do të vetë rregullojë lëvizjen e tij, duke dërguar komanda në bordin e Arduinos. Në varësi të sinjalit të pranuar të hyrjes, mikrokontrollori Arduino dërgon dronin ne një drejtim tjetër nëpërmjet drajverit të motorrit IC.

Fjalë çelës: dron, teknologji inovative Flexi-port, CC3D EVO, USB, Arduino.

\section{DRONE THE FUTURE IN YOUR HAND}

\section{Abstract}

A drone is an unmanned vehicle used by humans through controllers. The integration of drones and Internet of Things (IoT) has created different possibilities of use in various activities. In this project, we will use the sensor with simple speed and easily available STM32 32-bit micro-controller, which operates in 90MIP with $128 \mathrm{~KB}$ Flash and $20 \mathrm{~KB}$ RAM. With these parameters, the drone will be able to recognize the true status of the environment where it will be used. We will also enable automatic drone control. 
Ervis Qyra, Artur Prendi

With the help of a small servo motor, the drone scans the area on both the left and right side to find the best way to turn. Using the ultrasonic sensor, the drone will control the presence of obstacles and will self-regulate its movement, sending commands the Arduino. Depending on the received input signal, the Arduino microcontroller sends the drone in another direction via the IC engine.

Keywords: drone, innovative Flexi-port technology, CC3D EVO, USB, Arduino.

\section{Hyrje}

Rritja e përdorimit të droneve për qëllime komerciale dhe personale ka krijuar shqetësime për sigurinë dhe humbjen e kontrollit të droneve. Shqetësimet specifike rreth droneve që fluturojnë shumë afër avionëve komercialë kanë sjellë gjithashtu, thirrje për kufizime.

Në thelb, droni është një aparat fotografik. Radari i zbulimit të dronit dërgon një sinjal dhe merr reflektimin, matjen e drejtimit dhe distancën (pozicionin). Shumica e radarëve dërgojnë sinjalin e tyre radio si një shpërthim, pastaj dëgjohet “jehona". Pothuajse të gjithë radarët janë të dizenjuar për të mos kapur objektiva të vegjël. Ata janë krijuar për përcjelljen e objekteve të mëdha, si avionët e pasagjerëve $[1,2]$.

\section{Pjesët përbërëse të robotit}

F450 PCB është përpjekur të mundësojë përvojën me CC3D sa më lehtë dhe me sa më pak probleme të jetë e mundur. Natyrisht për një produkt të nivelit të lartë, pajisja është e plotë; nuk ka asgjë për të bashkuar. Rrjeti i përfshirë RC lejon të lidhet çdo marrës standard PWM. Të gjitha bordet e CopterControl janë testuar para transportit dhe vijnë me bootloader tashmë të ndezur.

Softueri OpenPilot është krijuar për t’u përdorur nga të gjithë, duke mundësuar instalimin në të gjitha sistemet kryesore operative, duke siguruar paketat e instalimit për to.

Droni ynë përbëhet nga komponentët e mëposhtëm:

1. CC3D EVO CopterControl, me një funksion të futjes direkte në marrësin satelitor, $\mathrm{i}$ cili nuk ka nevojë për kabllo konvertimi.

2. Mikrokontrollues i fuqishëm STM32 32-bit që funksionon në 90MIP me 128KB Flash dhe RAM 20KB.

3. Gyros me funksion të lartë dhe nxitës të shpejtësisë MEM me 3-akse.

4. PCB i vogël $36 \mathrm{mmx} 36 \mathrm{~mm}$ me katër shtresa për ulje elektrike dhe performancë fluturimi.

5. Mbështetje softuerësh për Windows, për Mac dhe Linux, për marrësit satelitor spektrum.

6. Mbështetje e pajisjeve Futaba S-BUS.

7. Teknologji inovative Flexi-port për fleksibilitet superior të portit. 
DRONI E ARDHMJA NË DORËN TËNDE

8. 4Mbits në bord EEPROM për ruajtjen e konfigurimit.

9. Flexiport, CopterControl.

10. Funksionet e ReceiverPort (të rregullueshme): 6 kanale hyrëse PWM ose rrymë të kombinuar PPM, 4 kanale daljeje PWM.

11. PWM në servos ose ESC, ose për stabilizimin e kamerës. Stabilizimi i kamerës: mbështetet në instalime kamerash deri në 3 akse me stabilizim dhe kontroll manual nga cilido prej marrësve të konfiguruar.

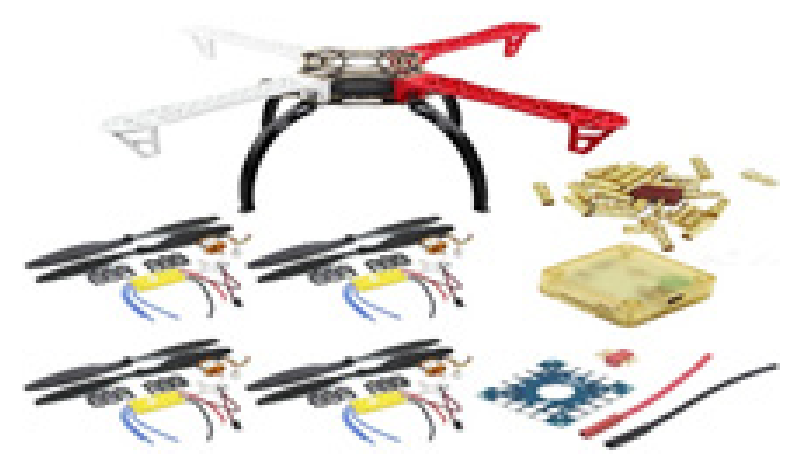

Figura 1. Pjesët përbërëse të dronit

\section{Zhvillimi i punës}

CC3D është një kontrollues i fuqishëm dhe përballon fluturimin e dronit. Është një sistem automatik i dizenjuar për shumë motorë duke siguruar vetënivelimin dhe mbajtjen në lartësi të mira, e cila e heq tërësisht stresin nga multirotorët fluturues RC si për aplikacione profesionale, ashtu edhe për hobi. Mund të instalohet në një larmi modelesh nga kuadrotori deri tek heksa-rotori duke përdorur Gyros me funksion të lartë me 3-akse MEM dhe nxitues të shpejtësisë MEM me 3-akse.

Në udhëzuesin e kontrolluesit të fluturimeve CC3D kemi pjesët si më poshtë:

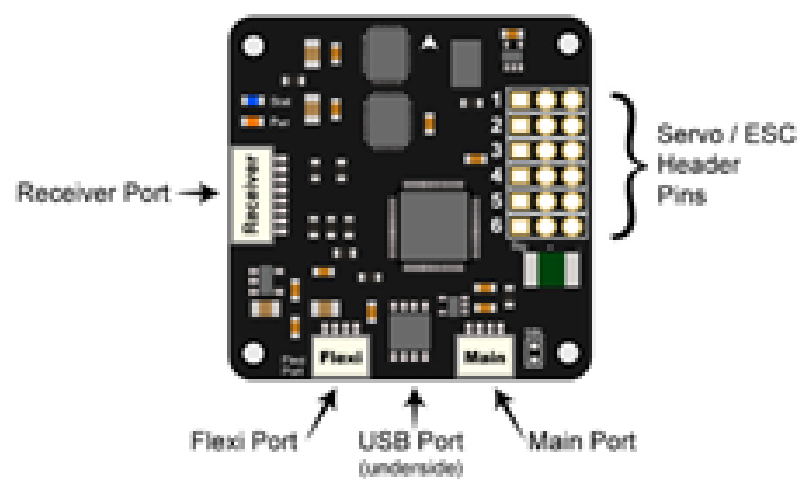

Figura 2. Pamja e kontrolluesit të fluturimeve CC3D 
Ervis Qyra, Artur Prendi

\section{Linja e kabllove të marrësit}

Më poshtë jepet figura, e cila shpjegon lidhjen e CC3D me marrësin pasi ngjyrat mund të ndryshojnë në varësi të furnitorit të bordit CC3D.

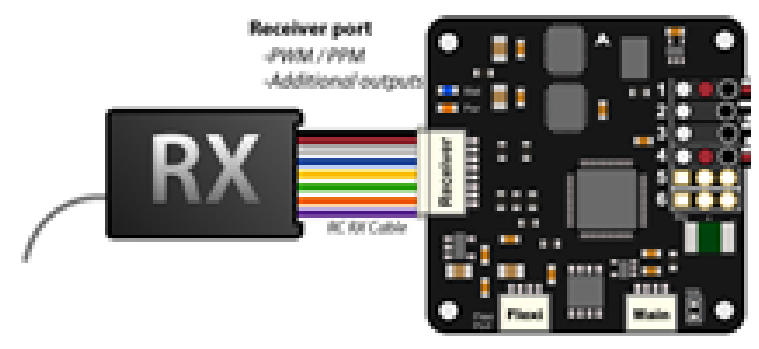

Figura 3. Lidhja e kabujve të marrësit

Marrësi PWM, duhet të lidhet me kabllot në mënyrë korrekte me marrësin. Imazhi më poshtë tregon numrat e kabllove dhe ku duhet të lidhen kabujt me marrësin. Numrat në figurën më poshtë korrespondojnë me atë kanal ku duhet të lidhen.

Nëse e rregullojmë kontrolluesin e fluturimit përmes lidhësve servo (duke përdorur funksionin BEC të kontrolluesit të shpejtësisë), drejtimi pozitiv i fuqisë nga vetëm një ESC është vërtet i nevojshëm. Të gjitha telat mund të lihen të paprekura dhe futen në bord pa ndonjë problem.

\section{Renditja dhe drejtimi i motorëve CC3D}

Stabilizimi i kamerës mbështet instalime kamerash deri në 3 boshte me stabilizim dhe kontroll manual nga cilido prej marrësve të konfiguruar.

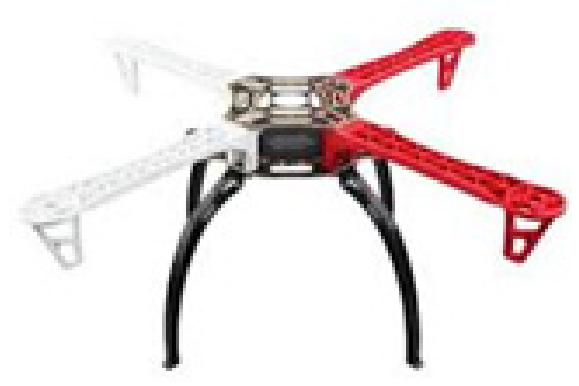

Figura 4. Ndërtimi i përfunduar i dronit

Paketa F450 përfshin gjithçka që nevojitet për të mbledhur një dron të fuqishëm me 450 klasa për argëtim ose fotografi. Kompleti përfshin kornizën, motorët, kontrolluesit 
DRONI E ARDHMJA NË DORËN TËNDE

elektrikë të shpejtësisë, bordin e shpërndarjes së energjisë, kabllot e ruajtjes së energjisë, dhe helmetën. Motorët dhe helmetët përputhen për konfigurimin e rekomanduar të baterisë. Moduli Arduino [3, 4, 5] programohet nëpërmjet gjuhës së programimit Arduino. Algoritmi është në gjendje të marrë informacionin nga transmetuesi, ta dëshifrojë atë dhe të japë sinjalin në njërën ose disa prej daljeve dixhitale, të cilat janë të lidhura me drajverin e motorave. Gjithashtu, edhe IC Attiny85 është programuar në ambientin e programimit Arduino, por në këtë rast është përdorur moduli Arduino MKR1000 për ngarkimin e kodit në IC Attiny85. Kur përdorim AnalogWrite me Arduino, rezultati do të jetë një sinjal PWM (Pulse Width Modulation).Një nga karakteristikat e një filtri të ulët të kalimit është se voltazhi analog do të ndryshojë gradualisht (kërkon ca kohë). Ky qark funksionon më mirë, sepse jep rezultatin e dëshiruar dhe përdor një sasi të ulët të pjesëve. Duke lidhur daljet e duhura me inputet e sakta në kontrolluesin PCB, sigurohemi që kemi marrë atë saktë përpara se të ngarkohet Sketch Arduino. Pasi të jetë lidhur gjithçka, mund të ngarkojmë skicën tonë në Arduino MKR1000.Arduino do të zëvendësojë bateritë dhe mund të dërgojë sinjale (si voltazhe) në shigjetat e anashkaluara. Në këtë moment mund të ndërtojmë programet tona duke eksperimentuar për të kontrolluar dronin me PWM.

\section{REKOMANDIME}

Për arsye se droni në fjalë është thjesht një prototip, nevojitet që të shtohen edhe sisteme të tjera që të jetë praktik dhe sa më funksional në një ambient pune të caktuar.

\section{SHËNIME}

Për arsye të mungesës së ekranit LCD, nuk mund të lexojmë shpejtësinë, distancën dhe këndin e kthimit të dronit.

\section{Referenca}

1. P. Nguyen, M. Ravindranatha, A. Nguyen, R. Han, and T. Vu, “Investi-gating cost-effective RF-based detection of drones," in Proc. ACM 2ndWorkshop Micro Aerial Vehicle Netë., Syst.,Appl. Civilian Use (DroNet), 2016.

2. M. Ezuma, F. Erden, C. K. Anjinappa, O. Ozdemir, and I. Guvenc, "Micro-UAV detection and classification from RF fingerprints usingmachine learning techniques," 2019, arXiv:1901.07703.

3. [Online]. Available: https://create.arduino.cc/projecthub/WesleyCMD/mind-controldrone-c8b28a?ref=tag\&amp;ref_id=drones\&amp;offset $=1$

4. Evans B., Beginning Arduino Programming (Technology in Action), Apress, 2011.S. Monk, Programming Arduino: Getting Started with Sketches, McGraw-Hill Education TAB; 2nd edition, 2016. 